\title{
Chromatographic and Computational Screening of Lipophilicity and Pharmacokinetics of Newly Synthesized Betulin-1,4-quinone Hybrids
}

\author{
Monika Kadela-Tomanek $^{1, * \mathbb{D}}$, Maria Jastrzębska ${ }^{2}$, Elwira Chrobak ${ }^{1}$, Ewa Bębenek ${ }^{1}$ and Stanisław Boryczka $^{1}$ \\ 1 Department of Organic Chemistry, Faculty of Pharmaceutical Sciences in Sosnowiec, \\ Medical University of Silesia, Katowice, 4 Jagiellońska Str., 41-200 Sosnowiec, Poland; \\ echrobak@sum.edu.pl (E.C.); ebebenek@sum.edu.pl (E.B.); boryczka@sum.edu.pl (S.B.) \\ 2 Silesian Center for Education and Interdisciplinary Research, Institute of Physics, University of Silesia, \\ 75 Pułku Piechoty 1a, 41-500 Chorzów, Poland; maria.jastrzebska@us.edu.pl \\ * Correspondence: mkadela@sum.edu.pl; Tel.: +48-364-16-66
}

Citation: Kadela-Tomanek, M.; Jastrzębska, M.; Chrobak, E.; Bębenek, E.; Boryczka, S. Chromatographic and Computational Screening of Lipophilicity and Pharmacokinetics of Newly Synthesized Betulin-1,4quinone Hybrids. Processes 2021, 9 , 376. https://doi.org/10.3390/ pr9020376

Academic Editor: Malgorzata Starek

Received: 16 January 2021

Accepted: 16 February 2021

Published: 19 February 2021

Publisher's Note: MDPI stays neutral with regard to jurisdictional claims in published maps and institutional affiliations.

Copyright: (c) 2021 by the authors. Licensee MDPI, Basel, Switzerland. This article is an open access article distributed under the terms and conditions of the Creative Commons Attribution (CC BY) license (https:// creativecommons.org/licenses/by/ $4.0 /)$.

\begin{abstract}
Lipophilicity is one of the most important parameters determining the pharmacodynamic and pharmacokinetic properties, as well as the toxicity of many compounds. The subject of the research was to determine the lipophilicity of betulin-1,4-quinone hybrids using thin layer chromatography in reverse phase system and computer programs to calculate its theoretical models. The correlation between the experimental and theoretical values of lipophilicity was analyzed. Lipinski's and Veber's rules, as well as penetration through the blood-brain barrier were also determined using computer programs. For all of the analyzed values, a similarity analysis was performed. The dendrograms for the experimental and theoretical lipophilicity show that there is a correlation between them. However, the dendrograms for the experimental lipophilicity and pharmacokinetic parameters indicate that there is no correlation between the structure and the pharmacological properties. Hybrids exhibit a high biological activity against cancer cell lines, with a high level of $\mathrm{NAD}[\mathrm{P}] \mathrm{H}$-quinone oxidoreductase (NQO1) protein. The enzymatic assay used has shown that these compounds are good NQO1 substrates, as evidenced by the increasing metabolic rates relative to that of streptonigrin. The similarity analysis has also shown that there is no correlation between lipophilicity and biological activity for the tested compounds.
\end{abstract}

Keywords: lipophilicity; betulin; 5,8-quinolinedione; NQO1 protein; ADMET

\section{Introduction}

Lipophilicity is one of the most important parameters determining the pharmacodynamic, pharmacokinetic, and toxicity parameters of many compounds. It determines the affinity of the molecule for the organic phase, which relates to the intermolecular interactions occurring between the solute and solvent molecules [1,2]. Lipophilicity can be determined by both direct and indirect methods. One of the direct methods is the shake-flask procedure, which determines lipophilicity as the relationship of the concentration of a compound in $n$-octanol and water. This method gives encouraging results, but it has many disadvantages, such as a tedious process, being time-consuming, a large amount of compound needed, and the requirement of a compound with a high purity. The indirect methods are based on chromatographic techniques, likes reversed-phase thin layer chromatography (RP-TLC), normal-phase thin layer chromatography (NP-TLC), and high-performance liquid chromatography (HPLC). The easy experimental procedure, low cost, and ability to test multiple compounds in a single run make RP-TLC the most used method to determine lipophilicity [2-8].

Betulin 1, derived from white species of birch bark, exhibits a wide spectrum of activity, including anticancer, antimicrobial, anti-viral, and anti-inflammatory properties. The 
chemical structure of betulin 1 contains four six-membered rings and one five-membered ring. Additionally, in their structure, there are two hydroxyl groups at the C-3 and C-28 positions, and an isopropenyl group at the $\mathrm{C}-19$ position (Figure 1). Modification at these positions can lead to new semi-synthetic derivatives, which exhibit a better biological activity and bioavailability $[9,10]$.

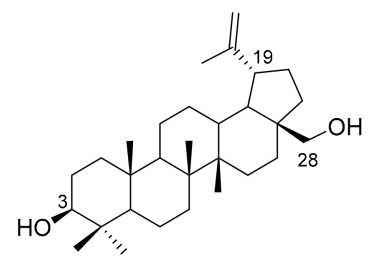

Figure 1. Structure of betulin $\mathbf{1}$.

Many articles on new hybrids of botulin, formed by combinations with other bioactive substances, like coumarin acid, ferrocene acid, artemisinin acid, and azidothymidine, have appeared in the literature in recent years. The combination of two active substances results in new hybrids with a better activity and low toxicity [11-15].

The lipophilicity of betulin derivatives was first described by Achrem-Achremowicz. This research showed that the lipophilic parameter depends on the type of substituent at the C-3 and C-28 positions, but the $\mathrm{pH}$ of the mobile phase does not affect the lipophilicity [16] According to the literature data, a relationship between the structure and lipophilicity of different mono- and di-substituted derivatives of betulin was found. This research showed that the substituent significantly affects the partition coefficient $(\log$ P). Moreover, the $\log \mathrm{P}$ value was also strongly affected by different pharmacokinetic properties, like polar surface, polarizability, molecular volume, and molecular refraction. In many cases, no correlation between the experimental lipophilicity and biological activity of the compounds was found $[4,6,17,18]$.

The present study aimed to determine the experimental and theoretical values of lipophilicity for betulin-1,4-quinone hybrids. The cluster analyses for the lipophilicity of hybrids allowed us to determine the relationship between the structure and lipophilic properties. Moreover, the correlation between the lipophilicity and pharmacokinetic properties was also analyzed. This study also conducted an analysis of the relationship between the biological properties, like anticancer activity and $\mathrm{NAD}(\mathrm{P}) \mathrm{H}$ :quinone oxidoreductase (NQO1), and lipophilicity of hybrids.

\section{Materials and Methods}

\subsection{Betulin-1,4-quinone Hybrids}

The analyzed compounds (2-16) were synthesized according to the procedure described in the literature [19]. The chemical structure of the hybrids is presented in Table 1. Briefly, betulin 1 and its derivatives were combined with 1,4-quinone in the presence of potassium carbonate in tetrahydrofuran. The structures of hybrids 2-16 were confirmed by spectroscopic methods, such as ${ }^{1} \mathrm{H}$ NMR, ${ }^{13} \mathrm{C}$ NMR, IR, and mass spectrometric (HR-MAS). The spectral data are consistent with those published in the literature [19].

\subsection{Chromatographic Analysis}

The lipophilic descriptor was determined using RP-TLC. A stationary phase was obtained by impregnating a silica gel RP- $18 \mathrm{~F}_{254} \mathrm{~S}$ layer with un-polar silicone oil. The (tris-hydroxymethyl)aminomethane $(0.2 \mathrm{M}, \mathrm{pH}=7.4)$ with acetone was used as the mobile phase. The percentage of acetone volume was varied within the range of $65-90 \%$ in $5 \%$ increments. Chromatographic chambers were filled with $60 \mathrm{~mL}$ of the mobile phase were and saturated with the vapors for $1 \mathrm{~h}$. 
Table 1. The chemical structure of hybrids $\mathbf{2 - 1 6 .}$

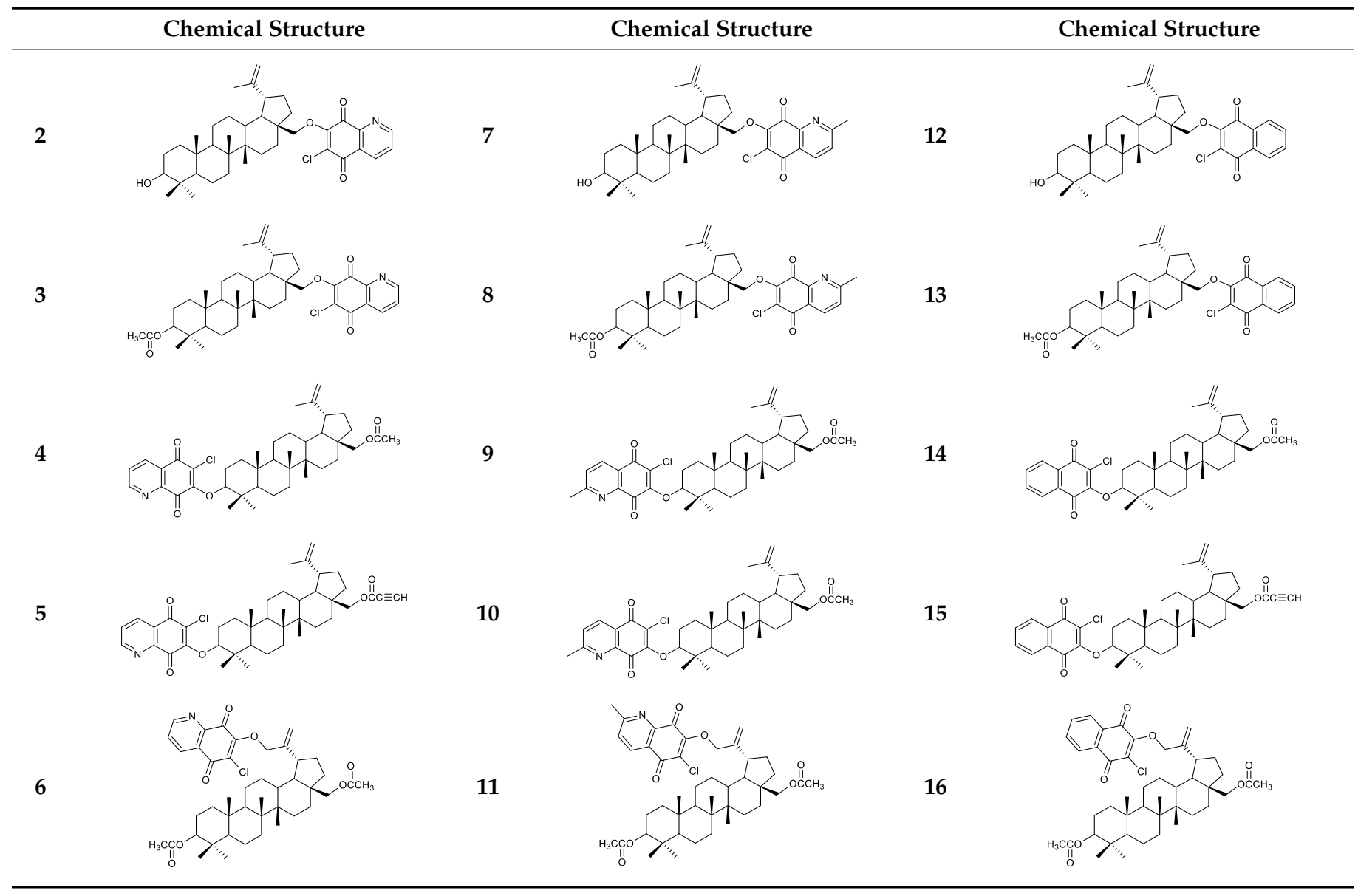

Compounds 1-16 were dissolved in chloroform $(2.0 \mathrm{mg} / \mathrm{mL})$, and a $2 \mu \mathrm{L}$ solution of the sample was applied on the chromatographic plates using a micropipette. The plates were placed in chromatographic chambers. The plates were developed up to a distance of $8.0 \mathrm{~cm}$ and then dried on a hot plate. Spots were visualized by spraying with $10 \%$ ethanol solution of sulphuric acid (VI) and then heated up to $110^{\circ} \mathrm{C}$.

The obtained values for the retardation factor $\left(R_{f}\right)$ were converted to the $R_{M}$ parameter according to Equation (1):

$$
\mathrm{R}_{\mathrm{M}}=\log \left(\frac{1}{\mathrm{R}_{\mathrm{f}}}-1\right)
$$

The $R_{M}$ parameters were calculated for every concentration of acetone and were extrapolated to zero concentration of an organic component in the mobile phase. The chromatographic parameter of lipophilicity $\left(\mathrm{R}_{\mathrm{M} 0}\right)$ was calculated using the SoczewińskiWachtmeister's Equation (2), as follows:

$$
\mathrm{R}_{\mathrm{M}}=\mathrm{R}_{\mathrm{M} 0}+b C
$$

where $\mathrm{C}$ is the concentration of acetone in the mobile phase, while $b$ is the slope of the regression plot.

The obtained $\mathrm{R}_{\mathrm{M} 0}$ and $b$ values were used to determine the chromatography hydrophobic index $\left(\phi_{0}\right)$ according to Equation (3):

$$
\varphi_{0}=-\frac{R_{M 0}}{\mathrm{~b}}
$$




\subsection{Computational Analysis}

The theoretical value of the lipophilicity descriptor for hybrids 2-16 and betulin 1 were determined using various online tools and available software, including ALOGPs, ACLOGP, ALOGP, miLogP, XLOGP2, XLOGP3, ACD/ $\log$, and MolLogP. Each program uses a different calculation method, but all of them take into consideration parameters related to the chemical structure [20-23]. The pharmacokinetic parameters were calculated using the pkCMS software [24].

\subsection{Enzymatic Assay}

Compounds 2-16 $(10 \mu \mathrm{mol} / \mathrm{L})$ were tested as NQO1 substrates using a NADPH recycling assay, as described in the literature $[25,26]$. The recombinant NQO1 (DT-diaphorase, EC 1.6.5.5, human recombinant, Sigma-Aldrich, Saint Louis, MO, USA) was used, and the oxidation of NADPH to $\mathrm{NADP}^{+}$was measured at an absorption wavelength of $340 \mathrm{~nm}$ on a BioTek 800TS microplate reader (BioKom, Janki, Poland). Compounds were dissolved in dimethyl sulfoxide $(2 \mu \mathrm{L})$ and then added to a 96-wall plate. NADPH $(400 \mu \mathrm{mol} / \mathrm{L})$ and NQO1 $(1.4 \mu \mathrm{g} / \mathrm{mL})$ in a $50 \mathrm{mmol} / \mathrm{L}$ potassium phosphate buffer $(\mathrm{pH}=7.4)$ were added to each well (198 $\mu \mathrm{L}$; Nunc Thermo Fisher Scientific, Waltham, MA, USA). Once the 96-well plate was filled with the assay solutions, excluding the NADPH solution, it was placed into the instrument and left to sit for $2 \mathrm{~min}$ before starting the measurements. The enzyme reaction was initiated by automated dispensing of the NADPH solution into the wells, and data were recorded at $10 \mathrm{~s}$ intervals for $10 \mathrm{~min}$ at $25^{\circ} \mathrm{C}$. The linear portion of the absorbance vs. time graphs (the first $20 \mathrm{~s}$ to $1 \mathrm{~min}$ ) was fitted, and the slops were calculated (velocity). The NADPH oxidation rates were compared with the reactions lacking compounds. The initial velocities were calculated and data were expressed as $\mu \mathrm{mol} \mathrm{NADPH} / \mu \mathrm{mol} \mathrm{NQO} 1 / \mathrm{min}$. All of the reactions were carried out at least in triplicate.

\subsection{Correlation and Cluster Analysis}

Based on the experimental and theoretical values of lipophilicity, as well as the enzymatic activity and molecular descriptor values, correlation and cluster analyses were performed. All data used for cluster analysis were standardized, and the cluster analysis was based on the Euclidean distance, using Ward's method. The analysis was carried out using Statistica 13.1 software.

\section{Results and Discussion}

Hybrids 2-16 and betulin 1 were analyzed using the RP-TLC method, and the $\mathrm{R}_{\mathrm{M} 0}$ and $b$ parameters were calculated based on Equations (1) and (2). The hydrophobic index $\left(\phi_{0}\right)$ for each compound was calculated according to Equation (3) (Table 2).

Table 2. The experimental values of the lipophilicity $\left(\mathrm{R}_{\mathrm{M} 0}\right.$ and $\left.\log \mathrm{P}_{\mathrm{TLC}}\right)$ and hydrophobic index $\left(\phi_{0}\right)$ for compounds 1-16.

\begin{tabular}{ccccccc}
\hline Compound & $\mathbf{R}_{\mathbf{M} 0}$ & $\boldsymbol{b}$ & $\mathbf{r}$ & $\mathbf{S D}$ & $\mathbf{l o g} \mathbf{P}_{\text {TLC }}$ & $\boldsymbol{\phi}_{\mathbf{0}}$ \\
\hline $\mathbf{1}$ & 4.54 & -0.05 & 0.979 & 0.028 & 5.34 & 90.37 \\
$\mathbf{2}$ & 5.49 & -0.06 & 0.995 & 0.022 & 6.36 & 92.52 \\
$\mathbf{3}$ & 6.52 & -0.07 & 0.994 & 0.023 & 7.46 & 93.10 \\
$\mathbf{4}$ & 6.42 & -0.07 & 0.996 & 0.015 & 7.36 & 89.31 \\
$\mathbf{5}$ & 6.62 & -0.07 & 0.994 & 0.021 & 7.58 & 93.69 \\
$\mathbf{6}$ & 5.86 & -0.07 & 0.998 & 0.012 & 6.75 & 95.74 \\
$\mathbf{7}$ & 5.69 & -0.06 & 0.992 & 0.023 & 6.58 & 95.74 \\
$\mathbf{8}$ & 6.49 & -0.07 & 0.997 & 0.019 & 7.43 & 90.72 \\
$\mathbf{9}$ & 6.42 & -0.07 & 0.996 & 0.009 & 7.36 & 90.92 \\
$\mathbf{1 0}$ & 6.80 & -0.07 & 0.995 & 0.025 & 7.77 & 95.00 \\
$\mathbf{1 1}$ & 6.77 & -0.08 & 0.994 & 0.011 & 7.74 & 90.71 \\
$\mathbf{1 2}$ & 6.46 & -0.07 & 0.987 & 0.027 & 7.41 & 92.85 \\
\hline
\end{tabular}


Table 2. Cont.

\begin{tabular}{ccccccc}
\hline Compound & $\mathbf{R}_{\mathbf{M} 0}$ & $\boldsymbol{b}$ & $\mathbf{r}$ & $\mathbf{S D}$ & $\mathbf{l o g} \mathbf{P}_{\mathbf{T L C}}$ & $\boldsymbol{\phi}_{\mathbf{0}}$ \\
\hline $\mathbf{1 3}$ & 7.12 & -0.07 & 0.995 & 0.023 & 8.12 & 93.10 \\
$\mathbf{1 4}$ & 7.13 & -0.07 & 0.995 & 0.019 & 8.14 & 88.67 \\
$\mathbf{1 5}$ & 6.82 & -0.08 & 0.982 & 0.014 & 7.19 & 91.54 \\
$\mathbf{1 6}$ & 6.26 & -0.07 & 0.973 & 0.029 & 7.80 & 87.09 \\
\hline
\end{tabular}

$b$ is the slope, $\mathrm{r}$ is the correlation coefficient, and SD is the standard deviation for the linear relationship of $\mathrm{R}_{\mathrm{M}}=\mathrm{R}_{\mathrm{M} 0}+b \mathrm{C}$.

In order to obtain the $\log \mathrm{P}_{\mathrm{TLC}}$ value, a calibration curve used needed. As standard substances, acetanilide, 4-bromoacetophenone, benzophenone, anthracene, dibenzyl, 9-phenylanthracene, and dichlorodiphenyltrichloroethane (DDT) were used, for which the literature $\log \mathrm{P}_{\text {lit }}$ values were in the range of 1.21-6.38 [27,28]. The $\mathrm{R}_{\mathrm{M} 0}$ for each standard compound was determined in the same condition as for hybrids $\mathbf{2 - 1 6}$ (Table 3 ).

Table 3. The experimental $\left(\mathrm{R}_{\mathrm{M} 0}\right.$ and $\left.\log \mathrm{P}_{\mathrm{TLC}}\right)$ and literature $\left(\log \mathrm{P}_{\text {lit }}\right)$ values of the standard compounds.

\begin{tabular}{ccccccc}
\hline Compound & $\log _{\text {lit }}$ & $\mathbf{R}_{\mathbf{M} \mathbf{0}}$ & $\boldsymbol{b}$ & $\mathbf{r}$ & $\mathbf{S D}$ & $\boldsymbol{\operatorname { l o g }} \mathbf{P}_{\mathbf{T L C}}$ \\
\hline Acetanilide & 1.21 & 0.68 & -0.02 & 0.985 & 0.015 & 1.17 \\
4-Bromoacetophenone & 2.43 & 1.87 & -0.02 & 0.981 & 0.018 & 2.46 \\
Benzophenone & 3.18 & 2.42 & -0.03 & 0.992 & 0.013 & 3.05 \\
Anthracene & 4.45 & 4.08 & -0.05 & 0.970 & 0.022 & 4.84 \\
Dibenzyl & 4.79 & 4.11 & -0.04 & 0.972 & 0.023 & 4.87 \\
9-Phenylanthracene & 6.01 & 4.87 & -0.06 & 0.985 & 0.019 & 5.69 \\
DDT & 6.38 & 5.50 & -0.06 & 0.975 & 0.019 & 6.37 \\
\hline
\end{tabular}

$b$ is the slope and $\mathrm{r}$ is the correlation coefficient for the linear relationship for $\mathrm{RM}=\mathrm{RM}_{0}+\mathrm{bC}$.

A linear relation between the literature $\log \mathrm{P}_{\text {lit }}$ and the experimental $\mathrm{R}_{\mathrm{M} 0}$ is described by Equation (4).

$$
\log \mathrm{P}_{\mathrm{TLC}}=1.0777 \mathrm{R}_{\mathrm{M} 0}+0.4407(\mathrm{r}=0.993 ; \mathrm{SD}=0.138)
$$

The calibration curve was used to calculate the $\log \mathrm{P}_{\mathrm{TLC}}$ value of hybrids $\mathbf{2 - 1 6}$ and betulin (1) (Table 2). In the group of tested compounds, betulin 1 showed the lowest lipophilicity parameter $\left(\log \mathrm{P}_{\mathrm{TLC}}=5.34\right)$. The introduction of 1,4-quinone moiety led to an increase in lipophilicity, resulting in $\log \mathrm{P}_{\mathrm{TLC}}$ in the range of 6.36-8.12.

In the group of betulin-5,8-quinolinedione hybrids (2-6), the lowest lipophilicity showed compound 2 containing the hydroxyl group at the C-3 position of the betulin moiety. The replacement of this hydroxyl group with an acetyl group caused an increase in lipophilicity. A comparison of $\log \mathrm{P}_{\mathrm{TLC}}$ for hybrids 3 and 4 showed that the elongation of the chain at the C-28 position created in an increase in lipophilicity. For hybrids 2-6, the order of the $\log \mathrm{P}_{\mathrm{TLC}}$ decrease was as follows: $5>4=3>6>2$. The introduction of the methyl group at the C-2' position of 5,8-quinolinedione moiety, as seen for compounds 7-11, led to a slight increase in lipophilicity. In this group of compounds, the lowest value of $\log \mathrm{P}_{\mathrm{TLC}}$ was exhibited by hybrid 7 . In the series of tested hybrids (2-16), the highest lipophilicity showed derivatives containing the 1,4-naphthoquinone moiety (12-16). For 12-16, the lowest lipophilicity was exhibited by compound 15, which contained the propynoiloxy moiety at the C-28 position of betulin. The obtained results show that lipophilicity depends on the type of 1,4-quinone, and follows the order 5,8-quinolinedione $>$ 2-methyl-5,8-qinolinedione $>1$ 1,4-naphthoquinone (Figure 2). 


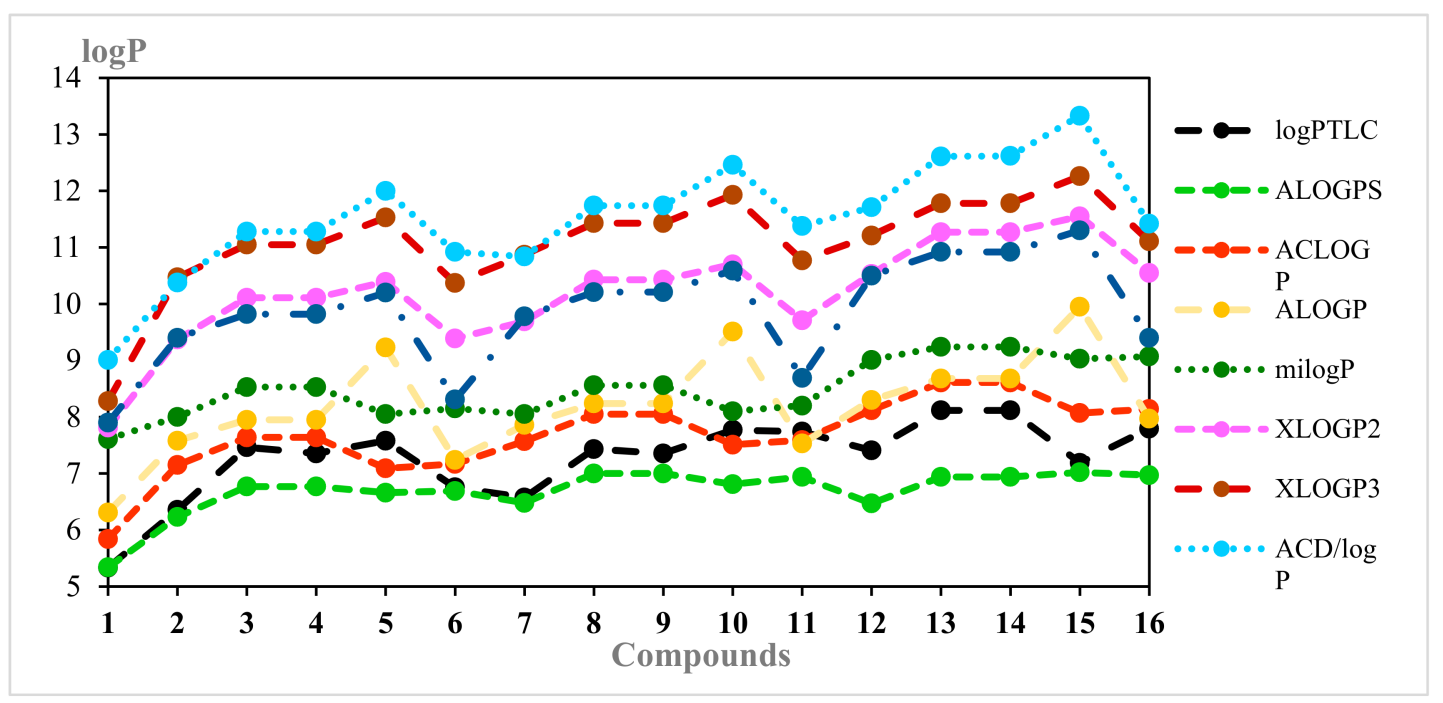

Figure 2. The profile of changes for the experimental and theoretical lipophilicity for hybrids 1-16.

Hydrophobicity is the capability of non-polar molecules or groups to form an association in water, and is measured by the hydrophobic index $\left(\phi_{0}\right)$. A higher index means that the compound is less soluble in water [3,29]. Hybrids $\mathbf{2 - 1 6}$ are characterized by a high value of $\phi_{0}$ index, which varies in the range of 88.67-95.74. A comparison of the hydrophobicity of betulin $1\left(\phi_{0}=87.09\right)$ and its derivatives (2-16) shows that the introduction of 1,4-quinone moiety slightly influenced their solubility in water.

The next step of the research was to determine the $\log \mathrm{P}$ parameter using the available computer software [20-23]. Depending on the mathematical module of the program used, the obtained values of the calculated $\log \mathrm{P}$ covered a wide range, from 5.34 to 13.33 (Table 4).

Table 4. The calculated value of lipophilicity for hybrids 2-16 and betulin $\mathbf{1}$.

\begin{tabular}{ccccccccc}
\hline Compound & ALOGPs & ACLOGP & ALOGP & miLogP & XLOGP2 & XLOGP3 & ACD/logP & MolLogP \\
\hline $\mathbf{1}$ & 5.34 & 5.84 & 6.31 & 7.61 & 7.81 & 8.28 & 9.01 & 7.90 \\
$\mathbf{2}$ & 6.23 & 7.15 & 7.58 & 8.00 & 9.37 & 10.47 & 10.38 & 9.40 \\
$\mathbf{3}$ & 6.77 & 7.64 & 7.95 & 8.53 & 10.11 & 11.05 & 11.28 & 9.82 \\
$\mathbf{4}$ & 6.77 & 7.64 & 7.95 & 8.53 & 10.11 & 11.05 & 11.28 & 9.82 \\
$\mathbf{5}$ & 6.66 & 7.09 & 9.23 & 8.05 & 10.39 & 11.53 & 12.00 & 10.20 \\
$\mathbf{6}$ & 6.69 & 7.17 & 7.24 & 8.15 & 9.39 & 10.37 & 10.92 & 8.31 \\
$\mathbf{7}$ & 6.48 & 7.57 & 7.86 & 8.05 & 9.69 & 10.87 & 10.84 & 9.78 \\
$\mathbf{8}$ & 7.00 & 8.05 & 8.24 & 8.56 & 10.43 & 11.43 & 11.74 & 10.21 \\
$\mathbf{9}$ & 7.00 & 8.05 & 8.24 & 8.56 & 10.43 & 11.43 & 11.74 & 10.21 \\
$\mathbf{1 0}$ & 6.81 & 7.51 & 9.51 & 8.10 & 10.70 & 11.93 & 12.46 & 10.59 \\
$\mathbf{1 1}$ & 6.94 & 7.59 & 7.53 & 8.20 & 9.71 & 10.77 & 11.38 & 8.69 \\
$\mathbf{1 2}$ & 6.47 & 8.12 & 8.30 & 9.01 & 10.53 & 11.21 & 11.71 & 10.50 \\
$\mathbf{1 3}$ & 6.94 & 8.61 & 8.68 & 9.24 & 11.27 & 11.78 & 12.61 & 10.92 \\
$\mathbf{1 4}$ & 6.94 & 8.61 & 8.68 & 9.24 & 11.27 & 11.78 & 12.62 & 10.92 \\
$\mathbf{1 5}$ & 7.02 & 8.07 & 9.95 & 9.03 & 11.55 & 12.26 & 13.33 & 11.30 \\
$\mathbf{1 6}$ & 6.97 & 8.14 & 7.97 & 9.07 & 10.55 & 11.11 & 11.42 \\
\hline
\end{tabular}

The highest values of lipophilicity were obtained using the ACD/logP program. However, the values that were the most similar to the experimental ones ( $\log \mathrm{P}_{\mathrm{TLC}}$ values), were found using the ACLOGP program (Figure 2). The presented calculations show that betulin 1 has the lowest lipophilicity, which is consistent with its $\log \mathrm{P}_{\mathrm{TLC}}$ value (Figure 2). The introduction of the 1,4-quinone moiety caused an increase in lipophilicity, which is consistent with experimental results. As shown in Figure 2, hybrids 5, 10, and 15 had the 
highest calculated value of lipophilicity. In addition, the lowest values were found for compounds 2, 6, and $\mathbf{1 1}$. These results are similar to the experimental results. In each group of compounds, there were hybrids with the same molecular formula, like 3 and 4,8 and 9, and 13 and 14 (Table 4 and Figure 2). In these cases, the calculated lipophilicity was the same for both compounds, regardless of the calculation method, but the experimental lipophilicity was different. These results show that in many cases, the theoretical calculation is not enough for the evaluation of the lipophilic parameters of compounds.

Table 5 presents the parameters of the correlation equation between $\log \mathrm{P}_{\mathrm{TLC}}$ and the calculated $\log$. The correlation coefficients are high $(r=0.864-0.815)$ for most programs. The exceptions are ALOGP, milogP, and MolLogP, for which the $r$ value varied in the range of $0.702-0.638$.

Table 5. Correlation equations for the relationship between the experimental $\left(\log \mathrm{P}_{\mathrm{TLC}}\right)$ and theoretically $\left(\log \mathrm{P}_{\text {calc }}\right)$ values of lipophilicity for compounds 1-16.

\begin{tabular}{cccc}
\hline Program & Correlation Equation & $\mathbf{r}$ & SD \\
\hline ALOGPS & $\log$ PTLC $=1.454$ LogPcalc -2.458 & 0.864 & 0.373 \\
ACLOGP & $\operatorname{logPTLC}=0.871$ LogPcalc +0.584 & 0.824 & 0.421 \\
ALOGP & $\operatorname{logPTLC}=0.513$ LogPcalc +3.068 & 0.638 & 0.571 \\
milogP & $\log P T L C=1.001$ LogPcalc -1.236 & 0.702 & 0.528 \\
XLOGP2 & $\operatorname{logPTLC}=0.666$ LogPcalc +0.475 & 0.842 & 0.401 \\
XLOGP3 & $\operatorname{logPTLC}=0.653$ LogPcalc +0.037 & 0.829 & 0.415 \\
ACD $/ \operatorname{logP}$ & $\operatorname{logPTLC}=0.575$ LogPcalc +0.633 & 0.815 & 0.430 \\
MolLogP & $\operatorname{logPTLC}=0.482$ LogPcalc +2.513 & 0.642 & 0.569 \\
\hline
\end{tabular}

The cluster analysis (similarity analysis) was performed for all of the results, for both the experimental and theoretical values of lipophilicity. The results are presented in Figure 3.

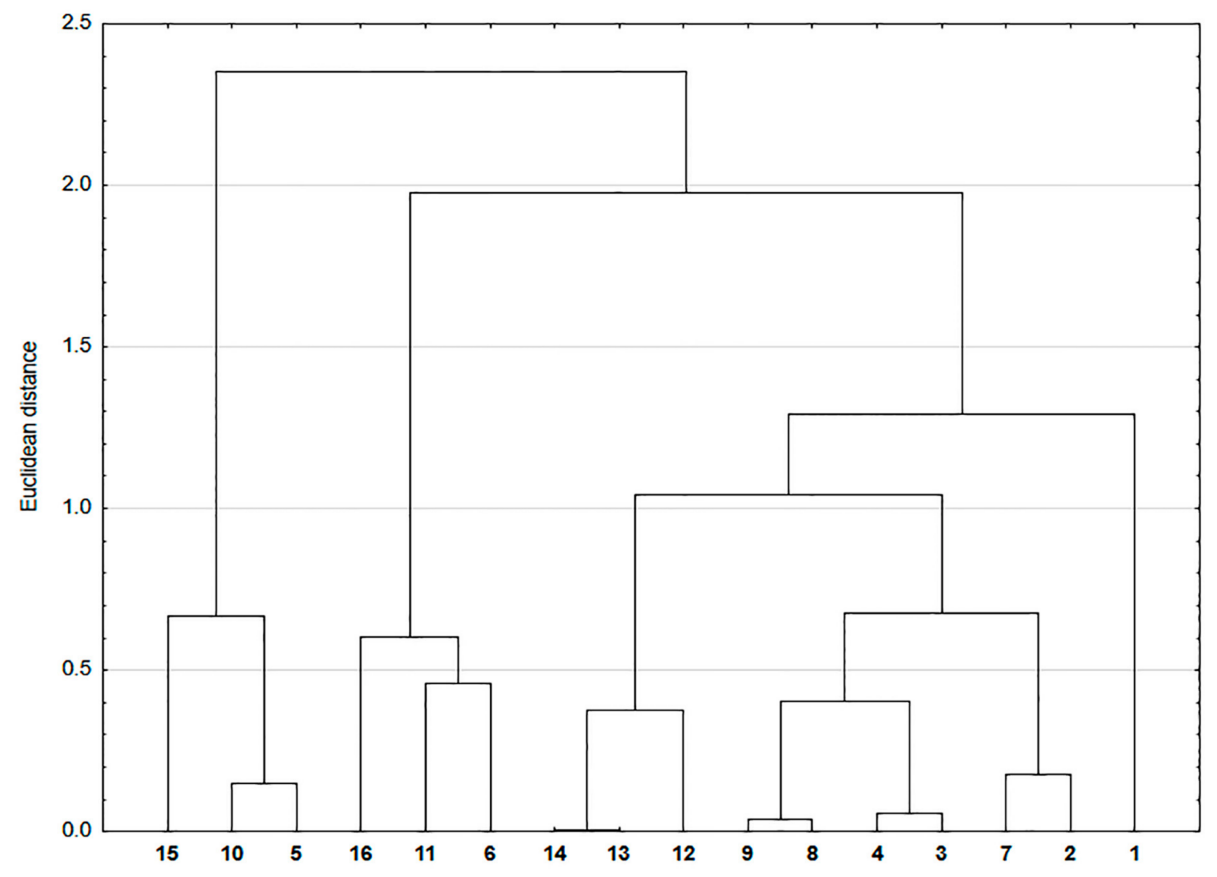

Figure 3. Similarity analysis of the experimental and theoretical values of lipophilicity for hybrids 2-16 and betulin 1 .

The similarity analysis shows three main clusters. The first consists of compounds 5 , 10 , and 15; the second 6, 11, and 16; and the third 1-4, 7-9, and 12-14. In the first and second clusters, hybrids are arranged according to the type of betulinyloxy fragment, which means 
that hybrids with 28-propynoyl-3-betulinyloxy and 3,28-diacetyl-30-betulinyloxy moieties have been recognized, respectively. In these two clusters, a strong relationship between lipophilicity and the structure of compounds can be observed. Derivatives 5, 10, and 15 have a different 1,4-quinone moiety at the C-3 position, while 6, 11, and 16 show structural similarity associated with the presence of the 1,4-quinone moiety at the C-30 position.

The third biggest cluster can be divided into two subclusters, and betulin (1), which differed from the others in this group. The first subcluster consists of 1,4-naphthoquinone compounds 12-14, and the second one of 5,8-quinolinedione (2-4) and 2-methyl-5,8quinolinedione (7-9) hybrids. Hybrids 2-4 and 7-9 show a similar value of lipophilicity. The similarity analysis shows a strong correlation between the lipophilicity and structure of the tested compounds (2-16).

The physicochemical parameters, such as molecular mass (M), topological polar surface area (TPSA), number of the donors (nHD) and acceptors (nHA) of the hydrogen bond, and number of rotatable bonds (nRT), are usually used to assess the absorption, distribution, metabolism, and excretion of the compound in the biological system [30-32]. An important property of the synthesized compounds is their penetration through the blood-brain barrier (BBB), which allows for predicting their neurotoxicity. All parameters were calculated using pkCMS software [24]. The results are presented in Table 6.

Table 6. The parameters determined by computational methods such as molecular mass (M), number of the donors (nHD) and acceptors (nHA) of the hydrogen bond, number of rotatable bonds (nRT), topological polar surface area (TPSA), and penetration drug by the blood-brain barrier (BBB; $\operatorname{logBB})$.

\begin{tabular}{ccccccc}
\hline Compound & $\mathbf{M}(\mathbf{g} / \mathbf{m o l})$ & nHD & nHA & nRT & TPSA $\left(\AA^{\mathbf{2}}\right)$ & $\log \mathbf{B B}$ \\
\hline $\mathbf{1}$ & 442.73 & 2 & 2 & 2 & 40.46 & -0.421 \\
$\mathbf{2}$ & 634.29 & 1 & 5 & 4 & 75.96 & -0.335 \\
$\mathbf{3}$ & 676.32 & 0 & 6 & 6 & 82.03 & -0.674 \\
$\mathbf{4}$ & 676.32 & 0 & 6 & 6 & 82.56 & -0.667 \\
$\mathbf{5}$ & 686.32 & 0 & 6 & 7 & 82.56 & -0.634 \\
$\mathbf{6}$ & 734.36 & 0 & 8 & 9 & 108.86 & -1.124 \\
$\mathbf{7}$ & 648.31 & 1 & 5 & 4 & 75.96 & -0.344 \\
$\mathbf{8}$ & 690.35 & 0 & 6 & 6 & 82.56 & -0.683 \\
$\mathbf{9}$ & 690.35 & 0 & 6 & 6 & 82.56 & -0.676 \\
$\mathbf{1 0}$ & 700.34 & 0 & 6 & 7 & 82.56 & -0.643 \\
$\mathbf{1 1}$ & 748.38 & 0 & 8 & 9 & 108.86 & -1.133 \\
$\mathbf{1 2}$ & 633.30 & 1 & 4 & 4 & 63.60 & -0.524 \\
$\mathbf{1 3}$ & 675.33 & 0 & 5 & 6 & 69.67 & -0.439 \\
$\mathbf{1 4}$ & 675.33 & 0 & 5 & 6 & 69.67 & -0.434 \\
$\mathbf{1 5}$ & 685.33 & 0 & 5 & 7 & 69.67 & -0.401 \\
$\mathbf{1 6}$ & 733.37 & 0 & 7 & 9 & 95.97 & -0.893 \\
\hline
\end{tabular}

Lipinski was the first researcher who studied the penetration of different compounds through biological membranes. He found that this penetration depends on the molecular mass of the compound, its lipophilicity, and the number of the donors and acceptors of hydrogen. Veber's rules are a modification of Lipiński's rules, and they introduce some changes, namely, the molecular mass has been replaced by the topological polar surface area and the number of rotatable bonds has been added [33,34]. Betulin 1 meets the mass criterion $(\mathrm{M}<500 \mathrm{~g} / \mathrm{mol})$, while the introduction of the 1,4-quinone moiety leads to an increase in molecular mass above $500 \mathrm{~g} / \mathrm{mol}$. All compounds 1-16 have less than 5 hydrogen bond donors ( $\mathrm{nHD}=0-2)$, less than 10 hydrogen bond acceptors (nHA $=2-8$ ), and less than 10 rotatable bonds (nRT $=2-9$ ), which means that these compounds meet Veber's criteria. A comparison of the nHD and nRT of betulin $\mathbf{1}$ and hybrids 2-16 shows that the introduction of the 1,4-quinone moiety causes an increase in both parameters. The TPSA of compounds 1-16 varies in the range of 40.46-108.86 $\AA^{2}$, which determines the high oral bioavailability [34]. According to the literature, if for a given compound the $\log B \mathrm{~B}>0.3$, it is considered to have the possibility of rapid penetration by the blood-brain 
barrier, if $\log \mathrm{BB}<-1$, there is a poor distribution to the brain $[35,36]$. The $\log B \mathrm{~B}$ values for hybrids $\mathbf{2 - 1 6}$ are lower than 0.3 , which suggests that these compounds could have a low permeability through BBB. Moreover, two of them, $\mathbf{6}$ and $\mathbf{1 1}$, show $\log \mathrm{BB}<-1$, which means they do not penetrate the central nervous system.

The correlation between $\log \mathrm{P}_{\mathrm{TLC}}$ and the calculated parameters is characterized by low regression coefficients $(r=0.066-0.624)$. The results indicate that there is no significant relationship between the lipophilicity and pharmacokinetic parameters. As an additional description of the analyzed hybrids (2-16), cluster analysis was performed, taking into account the experimental lipophilicity values and the physicochemical (M, nHA, nHD, nRT, and TPSA) and pharmacokinetics properties ( $\log B B)$. The results are presented in Figure 4.

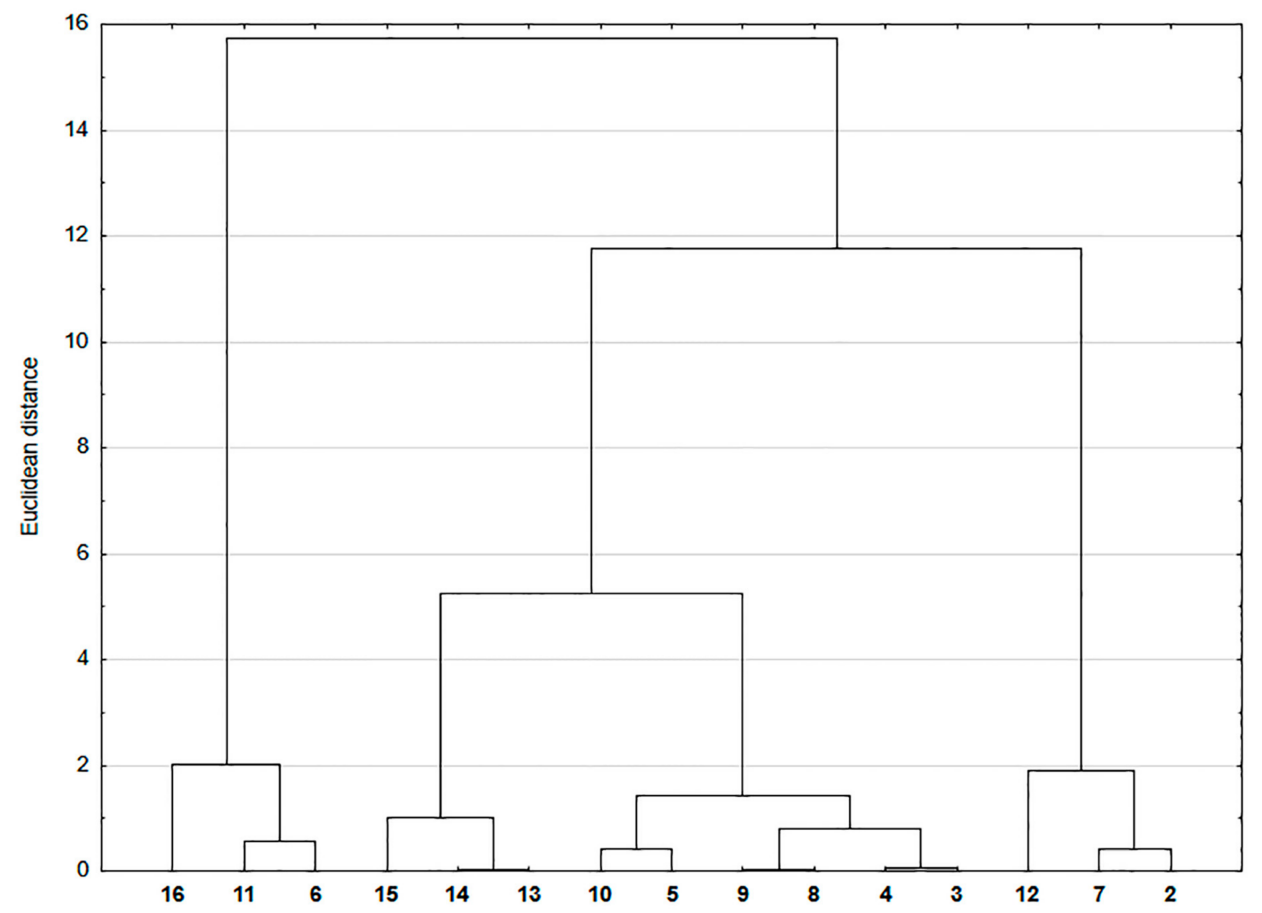

Figure 4. Similarity analysis for hybrids 2-16 investigated based on the experimental lipophilicity and the physicochemical (M, nHD, nHA, nRT, and TPSA) and pharmacokinetic properties (logBB).

As can be seen in Figure 4, there are several clusters. Compounds 6, 11, and 16, containing the 1,4-quinone moiety at the C-30 of 3,24-diacetyl-30-betulinyloxy, form the first cluster. Hybrids 13, 14, and 15 with the 1,4-naphthoquinone fragment at different positions of the betulinyloxy moiety, form another cluster. Derivatives 3-5 and 8-10 containing the 5,8-quinolinedione or 2-methyl-5,8-quinolinedione moiety in their structure, are the next cluster. The last cluster is formed by compounds with the 28-betulinyloxy moiety. The obtained results show that there is no correlation between the lipophilicity and pharmacokinetics parameters for the tested hybrids (2-16).

The next step of the research was the analysis of the biological activity of hybrids 2-16. It was found that derivatives 2-16, which exhibit a high anticancer activity against the lung cancer cell line (A549), also have a high level of the NOQ1 protein (Table 7) [19]. For this reason, all compounds were tested as a substrate of $\mathrm{NAD}[\mathrm{P}] \mathrm{H}$-quinone oxidoreductase 1 (NQO1). In this assay, hybrids at a concentration of $10 \mu \mathrm{mol} / \mathrm{L}$ were incubated with human NQO1 and NADPH. Streptonigrin was used as a reference compound. The results of the quinone reduction are expressed in units $\mu \mathrm{mol} \cdot \mathrm{L}^{-1} \mathrm{NADPH}$ oxidized $\cdot \mathrm{min}^{-1} \cdot \mu \mathrm{mol}^{-1}$ NQO1 in Table 7. 
Table 7. The NAD[P]H-quinone oxidoreductase 1 (NQO1) activity of hybrids 2-16 monitored at an absorbance at $\mathrm{A} 340 \mathrm{~nm}$.

\begin{tabular}{|c|c|c|}
\hline Compound & $\mathrm{A} 549 / \mathrm{IC}_{50}(\mu \mathrm{M})[19]$ & $\begin{array}{c}\text { NQO1 Activity } \\
\text { ( } \mu \mathrm{molNADPH} / \mu \mathrm{molNQ} 1 / \mathrm{min})\end{array}$ \\
\hline 1 & Neg. & $\mathrm{NO}$ \\
\hline 2 & $8.58 \pm 1.70$ & $1685 \pm 12$ \\
\hline 3 & $14.34 \pm 0.31$ & $1451 \pm 9$ \\
\hline 4 & $13.46 \pm 1.45$ & $1419 \pm 6$ \\
\hline 5 & $0.45 \pm 0.20$ & $2192 \pm 21$ \\
\hline 6 & $3.30 \pm 0.48$ & $1505 \pm 15$ \\
\hline 7 & $1.62 \pm 0.91$ & $1705 \pm 19$ \\
\hline 8 & $0.64 \pm 0.04$ & $2008 \pm 19$ \\
\hline 9 & $0.59 \pm 0.13$ & $1744 \pm 14$ \\
\hline 10 & $18.41 \pm 1.91$ & $1784 \pm 7$ \\
\hline 11 & $0.84 \pm 0.01$ & $1839 \pm 23$ \\
\hline 12 & $10.63 \pm 1.45$ & $1459 \pm 18$ \\
\hline 13 & $1.15 \pm 0.10$ & $1784 \pm 6$ \\
\hline 14 & $0.77 \pm 0.12$ & $2009 \pm 17$ \\
\hline 15 & $1.28 \pm 0.06$ & $1870 \pm 13$ \\
\hline 16 & $53.9 \pm 8.02$ & $1040 \pm 9$ \\
\hline Streptonigrin & $\mathrm{NO}$ & $621 \pm 32$ \\
\hline
\end{tabular}

Hybrids 2-16 show good reduction rates using NQO1, indicating that these compounds are good substrates for this protein. They show also higher metabolic rates $(1040-2192 \mu \mathrm{molNADPH} / \mu \mathrm{molNQO} 1 / \mathrm{min})$ in comparison with streptonigrin $(621 \mu \mathrm{molNADPH} / \mu \mathrm{molNQO} / \mathrm{min})$. In the group of 5,8-quinolinedione derivatives (2-6), hybrid 5 exhibits the highest enzymatic conversion rates, which are 3.5-time higher than for streptonigrin. Moreover, this compound exhibits a high activity against A549 cells. The introduction of the ethanoyl group at the C-28 position of botulin, instead of the propynoyl group (4 and 5), causes a decrease in the enzymatic conversion rates. A comparison of the 5,8-quinolinedione (2-6) and 2-methyl-5,8-quinolinedione (7-11) hybrids suggests that the introduction of the methyl group at the 5,8-quinonedione moiety causes an increase in enzymatic conversion rates. The exceptions are compounds $\mathbf{5}$ and $\mathbf{1 0}$, for which the introduction of the 5,8-quinolinedione moiety gives more active derivatives than those with the 2-methyl-5,8-quinolinedione moiety. In the group of the 1,4-naphthoquinone compound (12-16), derivative 14 shows the highest enzymatic conversion rates. The correlation of the NQO1 activity with $\mathrm{IC}_{50}$ values against $\mathrm{A} 549$ cells shows high regression coefficients $(r=0.773)$, suggesting that for this group of analogs, the anticancer activity refers to its interaction with the NQO1 protein.

The next step in the research was the analysis of the correlation between the experimental lipophilicity $\left(\log \mathrm{P}_{\mathrm{TLC}}\right)$, cytotoxic activity, and NQO1 activity. The calculated regression coefficient was low $(r=0.140-0.174)$, which means there is no significant relationship between lipophilicity and activity. The next similarity analysis was done for the experimental lipophilicity and biological activity ( $\mathrm{IC}_{50}$ and NQO1 activity; Figure 5).

Figure 5 shows that there are two main clusters. The first consists of compounds with a low value of NQO1 activity, like 3, 4, 6, 12, and 16. The second consists of hybrids 2, 5, 7-11, and 13-15; however, it is difficult to find the similarity in the structure of these derivatives. This result shows that there is no relationship between lipophilicity and the biological activity of hybrids $\mathbf{2}-\mathbf{1 6}$. 


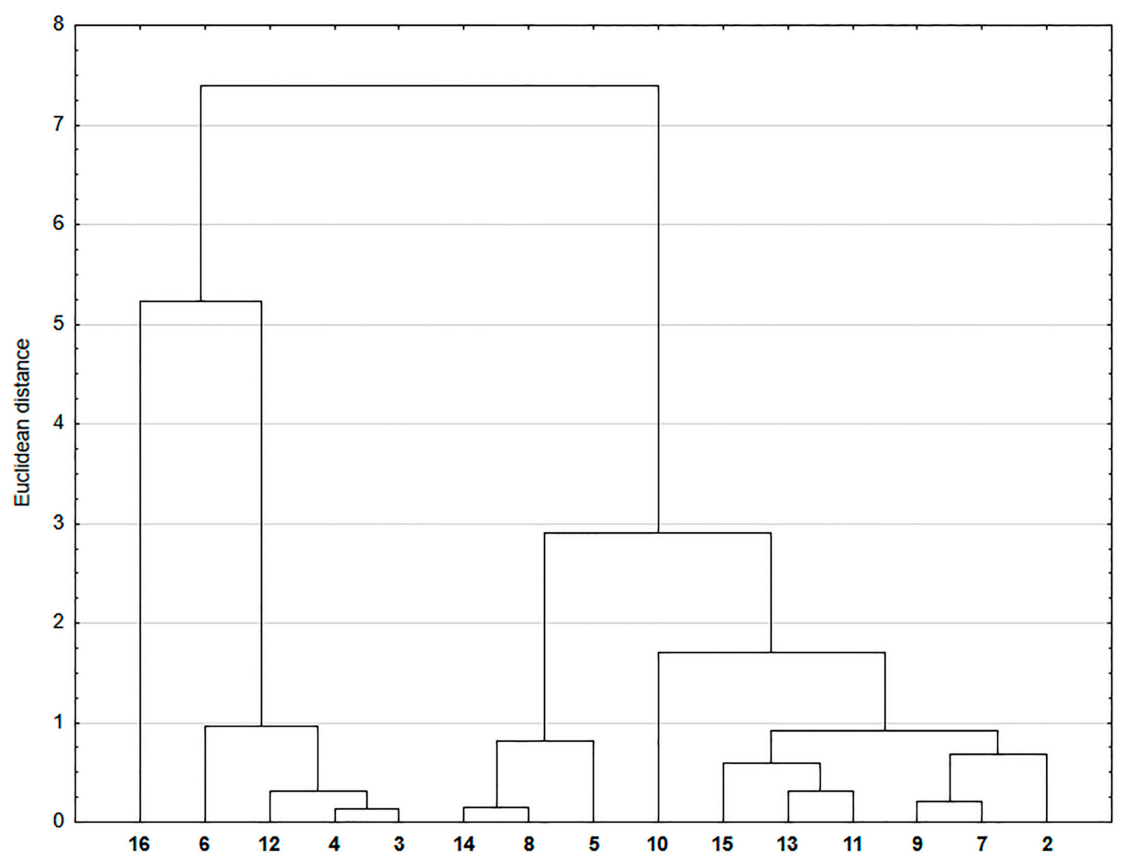

Figure 5. Similarity analysis for hybrids 2-16 investigated based on the experimental lipophilicity and biological activity $\left(\mathrm{IC}_{50}\right.$ and NQO1 activity).

\section{Conclusions}

In the presented study, the lipophilicity of betulin-1,4-quinone hybrids was determined and analyzed in terms of their structure, pharmacokinetic parameters, and anticancer and enzymatic activity. The introduction of 1,4-quinone moiety to the betulin structure caused an increase in lipophilicity. The cluster analysis showed that there is a strong relationship between the structure of compounds and both their experimental and calculated lipophilicity, which can serve to predict these values when designing new compounds. Additionally, Lipinski's and Veber's rules, supplemented by blood-brain penetration properties, were used to determine the bioavailability of hybrids 2-16. The obtained parameters suggest that the oral application could have some limitations because of the high value of the lipophilicity and molecular mass. The similarity analyses showed that lipophilicity does not correlate with the pharmacokinetic parameters.

The enzymatic study showed that hybrids $\mathbf{2} \mathbf{- 1 6}$ can be characterized as efficient substrates for the NQO1 protein. The correlation between the anticancer activity against lung cancer (A549) and the NQO1 activity shows that anticancer activity refers to its interaction with the NQO1 protein. Based on the similarity analysis, it has been found that there is no correlation between the biological activity and lipophilicity of the tested compounds.

Author Contributions: Conceptualization, M.K.-T. and S.B.; methodology, E.B. and E.C.; writingoriginal draft preparation, M.K.-T.; writing-review and editing, M.J. All authors have read and agreed to the published version of the manuscript.

Funding: This work was supported by the Medical University of Silesia in Katowice, Poland. Grant No PCN-2-006/K/0/S.

Institutional Review Board Statement: Not applicable.

Informed Consent Statement: Not applicable.

Data Availability Statement: The data presented in this study are available on request from the authors.

Conflicts of Interest: The authors declare no conflict of interest. 


\section{References}

1. Arnott, J.; Planey, S. The influence of lipophilicity in drug discovery and design. Expert Opin. Drug Discov. 2012, 7, 863-875. [CrossRef]

2. Bhatt, N.; Chavada, V.D.; Sanyal, M.; Shrivastav, P. Influence of organic modifier and separation modes for lipophilicityassessment of drugs using thin layer chromatography indices. J. Chromatogr. A 2018, 1571, 223-230. [CrossRef]

3. Rutkowska, E.; Pajak, K.; Jóźwiak, K. Lipophilicity-methods of determination and its role in medicinal chemistry. Acta Pol. Pharm. 2013, 70, 3-18.

4. Bębenek, E.; Bober-Majnusz, K.; Siudak, S.; Chrobak, E.; Kadela-Tomanek, M.; Wietrzyk, J.; Boryczka, S. Application of TLC to evaluate the lipophilicity of newly synthesized betulin derivatives. J. Chromatogr. Sci. 2020, 15, 117-126. [CrossRef] [PubMed]

5. Kadela-Tomanek, M.; Bober, K.; Bębenek, E.; Chrobak, E.; Boryczka, S. Application of thin-layer chromatography to evaluate the lipophilicity of 5,8-quinolinedione compounds. J. Planar Chromatogr.-Mod. TLC 2017, 30, 219-224. [CrossRef]

6. Bober, K.; Bębenek, E.; Boryczka, S. Application of TLC for evaluation of the lipophilicity of newly synthetized esters: Betulin derivatives. J. Anal. Methods Chem. 2019, 3, 1297659-1297667. [CrossRef] [PubMed]

7. Pyka, A. Evaluation of the lipophilicity of fat-soluble vitamins. J. Planar Chromatogr.-Med. TLC 2009, 22, 211-215. [CrossRef]

8. Šegan, S.; Andrić, F.; Radoičić, A.; Opsenica, D.; Šolaja, B.; Zlatović, M.; Milojković-Opsenica, D. Correlation between structure, retention and activity of cholic acid derived cis-trans isomeric bis-steroidal tetraoxanes. J. Sep. Sci. 2011, 34, 2659-2667. [CrossRef] [PubMed]

9. Hodon, J.; Borkova, L.; Pokorny, J.; Kazakova, A.; Urban, M. Design and synthesis of pentacyclic triterpene conjugates and their use in medicinal research. Eur. J. Med. Chem. 2019, 182, 111653-111678. [CrossRef]

10. Amiri, S.; Dastghaib, S.; Ahmadi, M.; Mehrbod, P.; Khadem, F.; Behrouj, H.; Aghanoori, M.R.; Machaj, F.; Ghamsari, M.; Rosik, J.; et al. Betulin and its derivatives as novel compounds with different pharmacological effects. Biotechnol. Adv. 2020, 38, 107409-107448. [CrossRef]

11. Gao, F.; Sun, Z.; Kong, F.; Xiao, J. Artemisinin-derived hybrids and their anticancer activity. Eur. J. Med. Chem. 2020, 188, 112044-112058. [CrossRef]

12. Xiao, J.; Sun, Z.; Kong, F.; Gao, F. Current scenario of ferrocene-containing hybrids for antimalarial activity. Eur. J. Med. Chem. 2020, 185, 111791-111802. [CrossRef] [PubMed]

13. Wang, G.Y.; Jin, L.; Piao, F.; Han, R. Betulin esters with coumarin-3-carboxylic and 3,4,5-trimethoxybenzoic acids. Mendeleev Commun. 2017, 27, 93-94. [CrossRef]

14. Bori, I.; Hung, H.; Qian, K.; Chen, C.; Morris-Natschke, S.; Lee, K. Anti-AIDS agents 88. Anti-HIV conjugates of betulin and betulinic acid with AZT prepared via click chemistry. Tetrahedron Lett. 2012, 53, 1987-1989. [CrossRef] [PubMed]

15. Xiong, J.; Kashiwada, Y.; Chen, C.; Qian, K.; Morris-Natschke, S.; Lee, K.; Takaishi, Y. Conjugates of betulin derivatives with AZT as potent anti-HIV agents. Bioorg. Med. Chem. 2010, 18, 6451-6469. [CrossRef]

16. Achrem-Achremowicz, J.; Kepczyńska, E.; Zylewski, M.; Janeczko, Z. Synthesis of betulin derivatives and the determination of their relative lipophilicities using reversed-phase thin-layer chromatography. Biomed. Chromatogr. 2010, 24, 261-267. [CrossRef]

17. Bildziukevich, U.; Vida, N.; Rárová, L.; Kolář, M.; Šaman, D.; Havlíček, L.; Drašar, P.; Wimmer, Z. Polyamine derivatives of betulinic acid and $\beta$-sitosterol: A comparative investigation. Steroids 2015, 100, 27-35. [CrossRef]

18. Thibeault, D.; Gauthier, C.; Legault, J.; Bouchard, J.; Dufour, P.; Pichette, A. Synthesis and structure-activity relationship study of cytotoxic germanicane- and lupane-type $3 \beta-\mathrm{O}$-monodesmosidic saponins starting from betulin. Bioorg. Med. Chem. 2007, 15, 6144-6157. [CrossRef] [PubMed]

19. Kadela-Tomanek, M.; Bębenek, E.; Chrobak, E.; Marciniec, K.; Latocha, M.; Kuśmierz, D.; Jastrzębska, M.; Boryczka, S. Betulin1,4-quinone hybrids: Synthesis, anticancer activity and molecular docking study with NQO1 enzyme. Eur. J. Med. Chem. 2019, 177, 302-315. [CrossRef]

20. Virtual Computational Chemistry Laboratory. Available online: http://www.vcclab.org/lab/alogps/ (accessed on 2 January 2021).

21. Molsoft, L.L.C. Available online: http://www.molsoft.com/ (accessed on 2 January 2021).

22. ACD/I-Lab. Available online: https://ilab.acdlabs.com/iLab2/ (accessed on 2 January 2021).

23. Molinspiration Cheminformatics. Available online: https://www.molinspiration.com/ (accessed on 2 January 2021).

24. pkCSM. Available online: http://biosig.unimelb.edu.au/pkcsm/prediction_single/ (accessed on 2 January 2021).

25. Li, X.; Bian, J.; Wang, N.; Qian, X.; Gu, J.; Mu, T.; Fan, J.; Yang, X.; Li, S.; Yang, T.; et al. Novel naphtho[2,1-d]oxazole-4,5-diones as NQO1 substrates with improved aqueous solubility: Design, synthesis, and in vivo antitumor evaluation. Bioorg. Med. Chem. 2016, 24, 1006-1013. [CrossRef]

26. Bian, J.; Deng, B.; Xu, L.; Xu, X.; Wang, N.; Hu, T.; Yao, Z.; Du, J.; Yang, L.; Lei, Y.; et al. 2-Substituted 3-methylnaphtho[1,2b]furan-4,5-diones as novel L-shaped ortho-quinone substrates for NAD(P)H:quinone oxidoreductase (NQO1). Eur. J. Med. Chem. 2014, 82, 56-67. [CrossRef]

27. Mannhold, R.; Cruciani, G.; Dross, K.; Rekker, R. Multivariate analysis of experimental and computational descriptors of molecular lipophilicity. J. Comput. Aided Mol. Des. 1998, 12, 573-581. [CrossRef] [PubMed]

28. Bodor, N.; Gabanyi, Z.; Wong, C.K. A new method for the estimation of partition coefficient. J. Am. Chem. Soc. 1989, 111, 3783-3786. [CrossRef] 
29. Constantinescu, T.; Lungu, C.; Lung, I. Lipophilicity as a central component of drug-like properties of chalchones and flavonoid derivatives. Molecules 2019, 24, 1505. [CrossRef] [PubMed]

30. Mälkiä, A.; Murtomäki, L.; Urtti, A.; Kontturi, K. Drug permeation in biomembranes: In vitro and in silico prediction and influence of physicochemical properties. Eur. J. Pharm. Sci. 2004, 23, 13-47. [CrossRef]

31. Alavijeh, M.; Chishty, M.; Qaiser, M.; Palmer, A. Drug metabolism and pharmacokinetics, the blood-brain barrier, and central nervous system drug discovery. NeuroRx 2005, 5, 554-571. [CrossRef] [PubMed]

32. Duchowicz, P.; Castro, E. QSPR studies on aqueous solubilities of drug-like compounds. Int. J. Mol. Sci. 2009, 10, $2558-2577$. [CrossRef] [PubMed]

33. Lipinski, C.; Lombardo, F.; Dominy, B.; Feeney, P. Experimental and computational approaches to estimate solubility and permeability in drug discovery and development settings. Adv. Drug Deliv. Rev. 1997, 23, 3-26. [CrossRef]

34. Veber, D.F.; Johnson, S.R.; Cheng, H.Y.; Smith, B.R.; Ward, K.W.; Kopple, K.D. Molecular properties that influence the oral bioavailability of drug candidates. J. Med. Chem. 2002, 45, 2615-2623. [CrossRef] [PubMed]

35. Kadela-Tomanek, M.; Bębenek, E.; Chrobak, E.; Latocha, M.; Boryczka, S. Alkoxy and enediyne derivatives containing 1,4benzoquinone subunits-synthesis and antitumor activity. Molecules 2017, 22, 447. [CrossRef]

36. Hutter, M.C. Prediction of blood-brain barrier permeation using quantum chemically derived information. J. Comput. Aided Mol. Des. 2003, 17, 415-433. [CrossRef] [PubMed] 